\title{
Screening Job Candidates With Social Media:
}

\section{A Manipulation of Disclosure Requests}

\author{
John R. Drake, East Carolina University, USA \\ Christopher P. Furner, East Carolina University, USA \\ (iD https://orcid.org/0000-0001-7074-4820
}

\begin{abstract}
With the proliferation of social media, job candidate screening and evaluation professionals have new avenues to gather information regarding job candidates. Job candidates recognize that recruiters will examine their social media, and tailor their profiles to foster a positive impression. However, recent popular press news suggests that some employers are taking social media screening to more invasive levels. This study seeks to evaluate how job candidates respond to social media screening from recruiters. Using a scenario-based experiment with 290 subjects, the authors tested relationships between candidate characteristics and trust in the recruiter as well as hesitancy to accept an offer. This research found that under all conditions, trust reduces hesitancy to accept the offer and that age reduces trust in the company. Further, this article found differences in the relationships between privacy protection competence, social media production and trusting stance on trust in the company based on the level of social media screening.
\end{abstract}

\section{KEYWORDS}

Human Resource, PLS, Privacy, Recruiting, Social Media, Trust

\section{INTRODUCTION}

According to Aral, Dellarocas, and Godes (2013, p. 3), Social Networking Sites (SNS) "represent one of the most transformative impacts of information technology on business, both within and outside firm boundaries." SNS are primary among the technologies which comprise Web 2.0, which has empowered non-technical users to create web-based content with only minimal effort and no financial cost. The use of SNS has grown substantially over the past decade (Dewan \& Ramaprasad, 2014; Pham, Tran, Thipwong, \& Huang, 2019), and as SNS use continues to grow, new uses for the information that they contain are being discovered.

Human Resource (HR) professionals are among those turning to SNS in order to augment the effectiveness of their efforts. While job recruiters have been using SNS to attract potential employees for some time (Gibbs, MacDonald, \& MacKay, 2015), HR professionals are increasingly using SNS to screen candidates. This raises a number of interesting research questions related to privacy concern and trust formation among job candidates (Suen, 2018).

According to the Bureau of National Affairs (2000), the top three priorities of HR professionals has been the recruiting, selection and placing of new employees for over 15 years. Recruiters are faced with a complex search and optimization problem under uncertainty: they must attempt to match 
the skill sets of job candidates with the skill needs of their organization, while constrained by their ability to attract candidates and constrained by uncertainty about the ability and motivation of any candidate to perform the activities which the organization needs to be performed.

While the recruiters are likely to have a strong sense of the requirements of the jobs which they are attempting to fill, the majority of the uncertainty that they face is in the ability and motivation of each candidate (Furner \& George, 2009). In the interest of securing offers, job candidates endeavor to present themselves in the most positive light possible, often times engaging in deception (Weiss \& Feldman, 2006). Increasingly, recruiters are using the social media profiles and activities of candidates as a means to reduce uncertainty about the candidates (Brown \& Vaughn, 2011). Through SNS, recruiters may be able to determine if the job candidate spends their free time studying, volunteering, or engaging in recreational behavior. Recruiters may also observe the relative stability of the candidate's personal relationships, their use of drugs and alcohol, or their proclivity to use language which might not reflect well on the company. Indeed, a few stories have indicated that recruiters have even gone so far as to request the SNS passwords of individuals applying for jobs (e.g. O'Dell, 2012).

Job candidates are also faced with a complex optimization problem under uncertainty. They attempt to elicit offers from multiple companies, then make tradeoffs between compensation, potential career growth opportunities, and potential job satisfaction. Assessing potential career growth and satisfaction is wrought with uncertainty, and as such, job candidates form attitudes about the employer based on their limited interactions with recruiters and managers. In this scenario, trust becomes a factor of primary importance to the job candidate, as it influences their proclivity to accept or decline a job offer (Celani, Deutsch-Salamon, \& Singh, 2008). Given the dynamic and evolving nature of SNS use by individuals and organizations, it is no surprise that research on the area is still immature. Indeed, Kluemper, Davison, Cao, and Wu (2015 p.61) contend that the study of the topic "has been substantially outpaced by organizational practice." As such, Kluemper et al. (2015) directly called for a research effort devoted to understanding the use of SNS in job candidate screening. This study represents a first step in answering that call.

Our research question is motivated by the lack of understanding about the effect of recruiter collection of SNS information about job candidates on the candidate's trust in the employer and willingness to accept a job offer (Drake, Hall, Becton, \& Posey, 2016).

RQ1: How does a recruiter's request for social media information influence a job candidate's trust in the employer and hesitancy to accept a job offer?

Within HR research, many studies have focused on the effects of recruiter behavior on trust formation, with little attention given to the characteristics of the job candidate (e.g. Celani et al., 2008; Van De Mieroop, 2018). Individuals differ in their proclivity to trust and in their expectations about privacy (Belanger \& Crossler, 2011; Drake, 2016; Keith, Babb, Furner, Abdullat, \& Lowry, 2016). We will argue that the SNS proficiency of a candidate and their reaction to recruiter SNS information seeking impacts trust in the employer. The dynamics of privacy perceptions and trust formation as they relate to SNS and job performance are complex and increasingly relevant as more people use SNS to interact (Poncy, Kim, Ramos, \& Lopez, 2017). Also, espoused national culture, and in particular uncertainty avoidance have been shown to influence trust in a number of contexts (Furner, Racherla, \& Zhu, 2014), including privacy (Belanger \& Crossler, 2011) and within a job interview context (Furner \& George, 2012). Our second research question is motivated by these findings:

RQ2: What individual characteristics influence a job candidate's trust in the employers and hesitancy to accept job offers? 
This study proceeds as follows: In the subsequent section, relevant literature related to job candidate screening, job fit, trust in a potential employer, uncertainty reduction theory and social media are discussed. Next, a model of trust in an employer, based on candidate characteristics as well as social media screening type is developed. This model is then tested and the methodology, analysis and results are presented. The results are then discussed in terms of theoretical and practical importance, and summarizing remarks conclude the paper.

\section{LITERATURE REVIEW}

Bateson, Wirtz, Burke, and Vaughan (2014) note that organizations devote extensive effort and resources to evaluating, selecting and negotiating with job candidates, since the consequences of a poor hire can be substantial. According to Kristof-Brown (2000), job candidate screening is conducted with the goal of maximizing both person-job fit (P-J fit) as well as person-organization fit (P-O fit). Assessing P-J fit involves matching the qualifications of job applications (their knowledge, skill and attitudes or KSA) with job requirements. Job requirements are furnished by hiring managers, while KSA qualifications are provided by candidates, largely from their resumes (Lauver \& Kristof-Brown, 2001). However, P-O fit is more difficult to assess, as it requires recruiters to make judgments about an individual's character and personality (Sekiguchi, 2004). Evaluating candidates in terms of personality and character is difficult, as substantial uncertainty exists. Indeed, assessing KSA involves some degree of uncertainty too, as research indicates that a large number of job candidates embellish or outright lie about their qualifications on their resumes and cover letters (Barrick, Shaffer, \& DeGrassi, 2009; Furner \& George, 2012; Levashina \& Campion, 2009). Indeed, Levashina and Campion (2009) report that of the 5.8 million resumes examined by placement firm ADP, $41 \%$ had factual errors related to education, experience or credentials. Studies have even pointed to impression management during interviews (Chen, Wen-Fen Yang, \& Lin, 2010). Overcoming this uncertainty to effectively evaluate $\mathrm{P}-\mathrm{J}$ and P-O fit is a primary goal of recruiters.

Uncertainty Reduction Theory (URT) (Berger, 1979) contends that when individuals are faced with a decision involving uncertainty (such as recruiters evaluating job candidates), they engage in either passive (observation) or active (information seeking) strategies to reduce uncertainty. HR researchers have identified a number of both passive and active uncertainty reduction strategies employed by recruiters (Ollington, Gibb, \& Harcourt, 2013). In exploring the use of technology in hiring, Chapman and Webster (2003 p. 113) find that "the use of HR technologies is in a state of flux with most organizations continuing to use a mix of traditional and technology-based HR methods" for candidate screening and selection. While more than half of hotel chains use SNS for job candidate recruitment (Gibbs et al., 2015), more and more are looking at the social media profiles of job candidates to evaluate their appropriateness for the job. With the proliferation of SNS, passive observation of several candidate characteristics which were previously difficult to assess is now possible. As Slovensky and Ross (2012) point out, individuals tend to use SNS for purposes other than seeking employment, and as such recruiters view SNS content as more "honest" and "valid" (p. 57) than resumes.

The content that candidates create using SNS may be useful for recruiters seeking to reduce uncertainty about the P-O fit of the candidate (Suen, 2018) as well as for decoding KSA. For instance, some SNS users make public conversations and pictures related to excessive use of alcohol or even illegal drugs. Other users engage in arguments with significant others publicly on SNS, which recruiters may view as an indication of instability and unreliability. Many SNS users use SNS to espouse political opinions (Hunter, 2011) which recruiters may fear will not reflect well on their company. Besides the red flags that SNS content may raise, information gleaned from SNS profiles can reinforce recruiters' positive evaluations of job candidates, for instance when a candidate comments on how hard they work and study or indicate that they experience satisfaction when they accomplish a goal. 
Recruiters are increasingly using SNS to screen job candidates (Kluemper, Rosen, \& Mossholder, 2012; Ollington et al., 2013) as well as admiting candidates for management colleges (Vatamanescu \& Constantin, 2015). Screening SNS is less time consuming and less prone to socially desirable distortion than the extensive personality tests typically employed by recruiters to assess P-O fit and KSA. Indeed, those personality tests can be "gamed" by candidates, who can respond in such a way as to make themselves appear to be a good fit (Ziegler, MacCann, \& Roberts, 2011). According to a 2009 survey by Careerbuilder.com, $45 \%$ of 2600 surveyed recruiters indicate that they use the SNS of candidates to reduce uncertainty about them (Grasz, 2009). This compares to $22 \%$ in 2008 . Indeed, Rowell (2010) finds that $70 \%$ of employers surveyed indicate that they had rejected a candidate because of his/her Facebook activities. While the publicly available information contained in SNS is valuable, job candidates are becoming more aware of this, and are crafting their profiles to create a positive impression in recruiters (Dutta, 2010). Job candidates have long engaged in impression management in their resumes and cover letters (Barrick et al., 2009), and savvy job candidates can use SNS as one more tool to augment their impression management efforts. One way that candidates can use SNS for impression management and still use them for their initial purpose is to control what recruiters see on SNS by restricting who can view the content of their profiles to those whom they identify as friends. For the recruiter, this mitigates the uncertainty reducing potential of SNS, as they are not privy to the full body of SNS content created by the candidate.

As recruiters become aware of candidate's use of impression management via SNS (Slovensky \& Ross, 2012), some have begun to ask candidates to connect with them on social media (Smith $\&$ Kidder, 2010), allowing the recruiters to see non-public content generated by the candidate and their connections. However, even if the candidate does connect with the recruiter, the candidate still has some degree of control over what content the recruiter sees. In order to overcome this hurdle, a few recruiters have turned to requesting that job candidates provide their SNS passwords in order to be considered for the position (O'Dell, 2012). Should a candidate provide their SNS passwords, recruiters will have access to that candidate's hidden group memberships, private posts, and personal message communications. This information would serve the interest of the recruiter very well, as it would be very effective at uncertainty reduction, however, many job candidates may view this degree of access as a potential invasion of privacy.

This study seeks to understand how a candidate's construal of the degree to which a recruiter violates their privacy will influence their trusting beliefs about that employer. Trust in the recruiter has been shown to influence job acceptance decisions in a number of other studies, and several employer, recruiter and situational factors have been shown to influence trusting beliefs. For example, Saks (1989) examines the influence of recruiter characteristics on job offer acceptance, and find that when recruiters give realistic job previews to the job candidates, candidates are more likely to accept the offer, even when the preview is less desirable. They note that this finding is consistent with Fisher, Ilgen, and Hoyer (1979), who attribute this effect to the candidates' perception of the recruiter's trustworthiness, knowledge and credibility (Fisher et al. found that recruiters who provide unfavorable written information about the job positively influences perceptions of trustworthiness). While a few authors have argued that recruiter trust can influence candidates' offer selection (Celani et al., 2008), a number of studies have tied employer trust to a variety of employee outcomes, including motivation (Eskildsen \& Dahlgaard, 2000) performance (Kurt T. Dirks \& Ferrin, 2002), satisfaction and commitment (Kurt T Dirks \& Ferrin, 2001), and knowledge sharing (Mooradian, Renzl, \& Matzler, 2006). This line of research makes it clear that facilitating trust in the employer early in the interview process is not only in the interest of the recruiter, but also in the interest of the organization.

Employer trustworthiness has been attributed to the extent to which a potential employer is seen as invasive by job candidates. A number of studies on the privacy perceptions of job candidates have indicated that job candidates tend to react negatively to requests for information from recruiters which are not related to the specific performance of the job they are applying to (i.e. P-J fit). For example, Mael, Connerley, and Morath (1996) demonstrated that job candidates view questions regarding 
intimacy, religion, personal traumatic events and biodata as “invasive.” Indeed, researchers have long been concerned about the invasiveness of selection procedures (Duffy, 1982).

Suen (2018) uses perceptions of procedural justice and control to investigate job candidates' attitudes regarding SNS screening, and ultimately withdraw intention. Using a sample of 201 employed Facebook users from Taiwan, Suen finds that job candidates who express stronger feelings of control of their SNS information also report weaker feelings of privacy invasion. Suen also finds that when job candidates are informed that SNS screening will occur, they have stronger feelings of fairness and lower intention to withdraw from the search than the candidates would if the SNS screening were done in secret. While Suen's study provides a foundation for ours, our study differs in a number of ways. Primarily, Suen uses self-reported feelings of control as an independent variable (the items used measured the participants perceived knowledge of privacy settings on Facebook), while we manipulate the level of social media screening.

While the influence of employee trustworthiness on job candidate's hesitancy to accept an offer has been well studied, the recency of the social media screening phenomenon has led to the development of a new and increasingly relevant area for study. In the next section, we develop a model of trust in the employer and job offer acceptance hesitancy, which is determined by four job candidate characteristics, and moderated by employer social media screening.

\section{MODEL AND HYPOTHESIS DEVELOPMENT}

Recruiters have to balance their own information seeking needs with their ability to not only attract, but also persuade qualified job candidates to accept an offer. With the goal of assisting recruiters in understanding how their espoused social media screening activities influence candidates' trust and hesitancy to accept an offer. We answer our research questions, by constructing a model which consists of five hypothesized direct relationships, along with five additional hypotheses moderated by three request types of social media screening (request to view public information, request to connect, or request for password). This model is illustrated in Figure 1.

\section{Hypotheses}

Trust in an employer changes over time based on interactions and observations (De Cremer \& Tyler, 2007). In general, employees with fewer years of service have higher levels of trust than employees with more years of service (Nichos, Danford, \& Tasiran, 2009). The younger generation has grown up with social media integrated with their lives and are used to sharing information and communicating broadly. This technological competency leads younger job candidates to trust employers more implicitly. As such, we hypothesize:

H1: The younger a job candidate, the more likely they will trust an employer, regardless of social media request type.

Younger job candidates, with an increased usage of social media for career planning (Poncy et al., 2017), become less suspicious of employer requests for personal information. As such, we predict that the screening requests will have a lesser impact on their trust in the employer. Older job candidates are more likely to have witnessed cases where too much information sharing has impacted a relationship. As such we predict that for these candidates, the impact of the screening request on trust is likely to be larger. Further, consistent with Robinson (1996), we predict that these impacts will be much greater when trust is already low. 


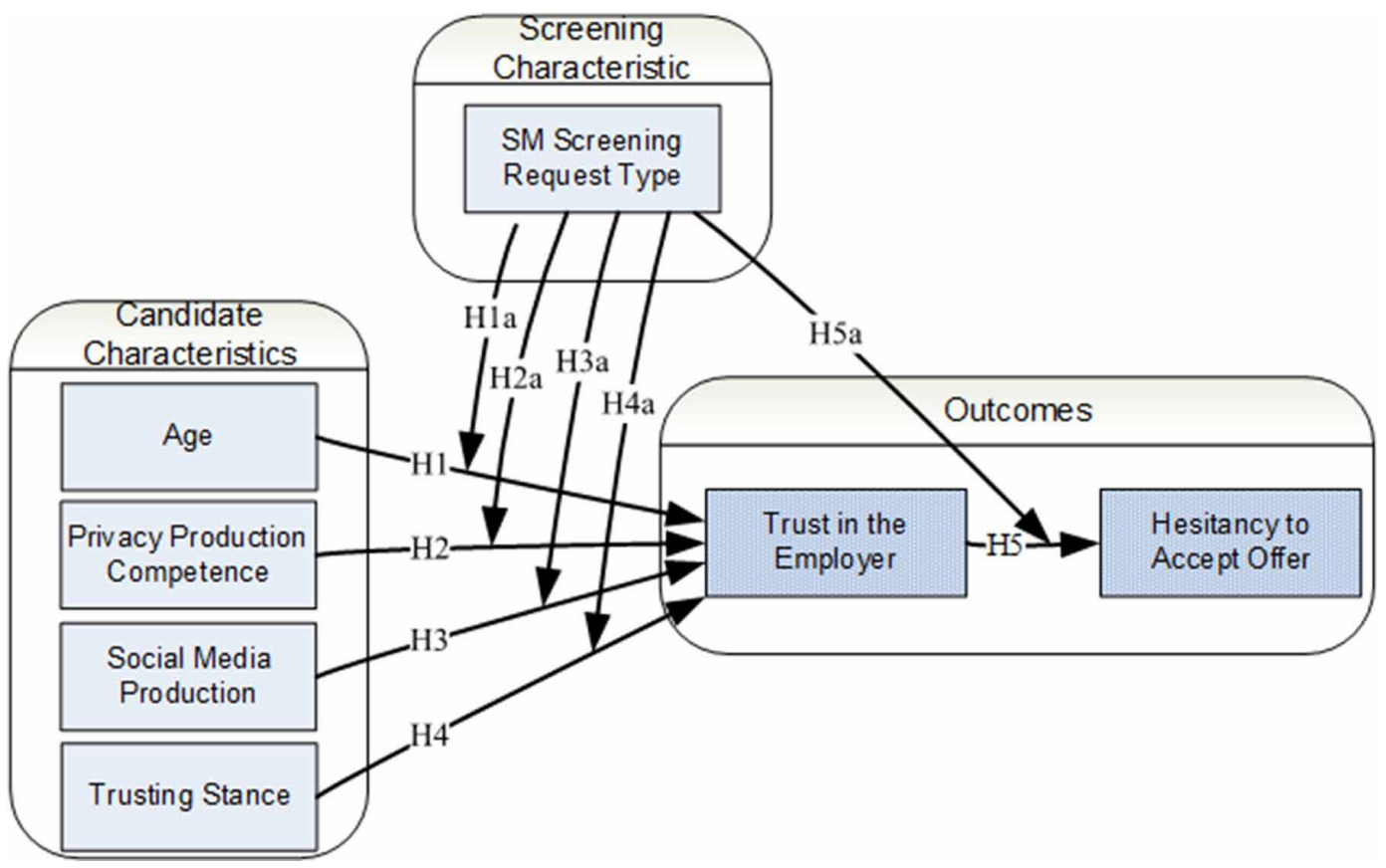

H1a-c: As the age of the job candidate increases, more intrusive request types will have a larger impact on trust (view request-connect request, view request-password request, and connect request-password request).

Privacy Protection Competence (PPC) is based on Roger's (1975) protection motivation theory and is a perception of how competent other individuals are at protecting their privacy. It is an adaptation of McKnight et al.'s (2002) competence based trusting disposition which was developed to measure the privacy concerns of individuals in other online contexts (Drake et al., 2016). Since individuals who score high on PPC believe that others have the ability to protect them from the harm associated with information disclosure, we predict that this confidence will cause them to experience lower levels of uncertainty and thus greater trust in the employer. Individuals with low PPC perceptions will experience feelings of vulnerability because they are not as confident in the employer's ability to protect the candidates' personal information from the potential harm associated with disclosure. As such, we predict:

H2: An individual's privacy protection competence will increase trust in an employer, regardless of social media request type.

When an individual begins to experience concern that another entity might act opportunistically and in doing so, harm the individual, their trust in that other entity is reduced (Morgan \& Hunt, 1994). We contend that this relationship will hold, even if the individual believes that the other entity has the capacity to avoid that harm. Since we predict that more invasive forms of social media screening will lead the job candidate to believe that the employer values organizational success more than the privacy of job candidates, the employer's ability to protect the candidate's personal and social information will not matter as much as their motivation. On the other hand, in situations where the employer is 
not seeking invasive information, the job candidate will not question the employer's motivation, and will only be concerned with their ability to protect their information (Sampson \& Lumsden, 2000).

H2a-c: As the social media request type becomes more intrusive (view request-connect request, view request-password request, and connect request-password request), the privacy protection competence will be a weaker predictor of trust in an employer.

Social Media Production (SMP) is a measure of the extent to which an individual creates new SNS content. It includes how frequently an individual writes on blogs, comments on blogs, micro-blogs, participates in Wiki-based projects, answers questions in question and answer communities, shares content in SNS, and updates SNS profiles. As an individual produces more content there are two interacting effects on trust. First, because more information has been disclosed through production, individuals may become desensitized to opportunistic human behavior. Alternatively, individuals who produce more content in social media may have a better understanding of privacy settings and use them more frequently. Considering that increasing use of social media tends to increase trust in general (Bohler \& Drake, 2017), we suspect that social media production of a job candidate will increase trust in an employer, regardless of the screening type.

H3: Higher levels of social media production by a job candidate will increase trust in an employer, regardless of social media request type.

Since more SMP increases the likelihood that an employer will find something which would hurt the candidate's chances of receiving an offer (such as a politically offensive post, an embarrassing picture, discussion of an unprofessional activity by friends, etc.), we predict that individuals who report more SMP will experience more anxiety when informed of each of the SNS screening activities, and as such, will report lower levels of trust in the employer.

H3a-c: As the social media request type becomes more intrusive (view request-connect request, view request-password request, and connect request-password request), the social media production of a job candidate will have a negative effect on trust in an employer.

Trusting stance, also referred to as disposition to trust, has been shown to be an individual characteristic which influences specific trust outcomes in a number of studies (Gefen, 2000; McKnight, Cummings, \& Chervany, 1998; Rotter, 1971). Gefen (2000, p. 728) defines it as “... a general, i.e. not situation specific, inclination to display faith in humanity and to adopt a trusting stance toward others." Using this construct allows researchers to account for trusting behaviors at an individual level, before introducing situation specific factors which can influence trust. Consistent with these findings, we intend to first test the impact of the candidate's trusting stance on trust in the employer, before testing the impact of more intrusive social media screening. Specifically, we predict, consistent with the findings of (McKnight et al., 1998) and Gefen (2000) that trusting stance will increase trust in the employer, across all levels of social media screening.

H4: The trusting stance of the job candidate will increase trust in an employer, regardless of social media request type.

Since trusting stance refers to a general proclivity to exhibit trusting behaviors before consideration of situational factors (Gefen, 2000), and since more intrusive forms of social media screening is a situational factor that is predicted to set off alarms in the minds of job candidates, we predict that trusting stance will have a larger impact on trust formation in situations where social media screening 
is more intrusive. This is because as candidates are asked for more invasive access to their social media content, they will experience more privacy concerns, consistent with Stewart and Segars (2002).

H4a-c: As the social media request type becomes more intrusive (view request-connect request, view request-password request, and connect request-password request), the trusting stance of the job candidate will be a stronger predictor of trust in an employer.

In addition to positioning themselves in the best possible way to obtain a job offer, job candidates are faced with an optimization problem involving substantial uncertainty. They must evaluate the offers that receive against each other based several factors, including salary, potential for career advancement as well as the potential for job satisfaction, all based on limited information. To overcome this uncertainty, the candidate may engage in active or passive information seeking behaviors.

Pavlou (2003) and McKnight et al. (2002) note that in an e-commerce context, trust serves as a heuristic allowing an actor to engage in a mutual interaction despite uncertainty about potential behaviors of the other party. This is consistent with findings in areas from organizational strategic alliances (Das \& Teng, 1998) to job performance (Colquitt, Scott, \& LePine, 2007), which view trust as an catalyst for action despite risks. Indeed Johnson-George and Swap (1982, p. 1306) contend that "...willingness to take risks may be one of the few characteristics common to all trust situations." We contend that these same, well studied dynamics will come into play when a job candidate has to decide if they want to accept a job offer. We predict that those candidates that trust the employer will be less hesitant to accept an offer, effectively being more willing to act in the face of uncertainty regarding their potential for job satisfaction.

H5: Trust in an employer will reduce hesitancy to accept a job offer, regardless of the social media request type.

We also propose that when interviewers request increasingly invasive access to social media information, those acts serve to reduce uncertainty in the minds of the job candidates about the potential for job satisfaction. Specifically, the more invasive requests serve as a signal that the employer may be exploitive, that they may value the success of the organization above the comfort and interests of their employees, and that the company has a Machiavellian culture. We propose that this uncertainty reduction will lead to increased hesitancy to accept the job offer, even when the candidate reports higher levels of trust in the employer.

H5a-c: When the social media request type is more intrusive (view request-connect request, view request-password request, and connect request-password request), trust in an employer will be a weaker predictor in the hesitancy to accept a job offer.

\section{METHODOLOGY}

In order to test our model, we conducted a scenario-based experiment in which subjects were asked to pretend that they were job candidates and had just completed an interview. This experiment is described in the following subsection.

\section{Research Design}

All hypotheses were tested using an online questionnaire, administered through Qualtrics. Participants were solicited through email. Our target sample were job candidates; therefore, we collected data from upper level undergraduate business majors and MBA students, because they were likely searching for jobs, would be searching for jobs in the near future, or were likely discussing job opportunities with 
friends. Additionally, the target sample generally uses social media more than the general population, making the context of the study more relatable (Duggan \& Brenner, 2013). Students were offered extra credit for participation.

The survey started with a series of questions about the participants' perceived competence of professionals to protect their privacy, the participants trusting stance towards strangers, the participant's social media usage, and their age. They were then randomly assigned to one of three vignettes. Each vignette asked the participant to pretend that they were interviewing for a job, and that the interviewer had informed them of their social media screening policy. The vignettes contained differing types of social media screening, each with increasing levels of information disclosure. In the first vignette, the participants were informed that the interviewer would view the participants' public social media profiles. In the second vignette, the participants were asked to connect on the social media platform so that the interviewer could view the profile in more detail. In the third vignette, the participants were asked to provide their username and password to the social media platform.

After being presented with the vignette, participants were asked how much they trusted the employer, and if they would be hesitant to accept an offer from that employer.

\section{Instrument Development}

The questionnaire used in this study was developed from existing instruments which were adapted to a social media privacy context. The privacy protection competence and trusting stance measures were adapted from sub-constructs of trusting disposition (McKnight et al., 2002), set on a 7 point scale from strongly agree to strongly disagree. Trust in the employer was adapted from Sarker, Ahuja, Sarker, and Kirkeby (2011).

Social media production consisted of a formative construct of 8 items asking about the creation of social media content on various social media platforms. Items asked about posting on social networks; writing comments on social network posts; changing information on a wiki page; providing answers using a social bookmarking site; writing, ratings, reviews, or testimonials; writing blog posts; commenting on blog posts; and posting on micro-blog. These were captured on a 5-point scale from "Never" to "Very Often." Because participants tend to emphasize one platform over another, the construct Social Media Production was formed by the items and did not covary with each other (Peters, Straub, \& Rai, 2007).

Hesitancy to Accept was a two-item measure assessing how hesitant the participant would be to accept a job offer from the employer if 1) they had not received any other job offers, and 2) they had two equally appealing job offers (Table 1).

\section{Sample}

Undergraduate and graduate students at a large university in the southeastern United States were invited to participate (see Figure 2, Figure 3, and Figure 4). 304 participants started the survey with 290 usable responses. All participants were informed of their rights as research subjects and guaranteed confidentiality of their information. Participants were randomly assigned to one of three experimental scenarios described in the research design above.

\section{ANALYSIS AND RESULTS}

We conducted our analysis using PLS-MGA. PLS provides a means to analyze complex predictive relationships between latent variables. PLS analysis is appropriate for situations with high complexity and when theoretical explanations are scarce (Vinzi, Chin, Henseler, \& Wang, 2010), as is the case with our study. Our study also uses a formative construct with a non-normal distribution that could not be re-specified in CB-SEM, requiring PLS analysis (Gefen, Rigdon, \& Straub, 2011; Hair, Hult, Ringle, \& Sarstedt, 2014). PLS-MGA provides a non-parametric technique for comparing groups within PLS that do not contain the same distributional assumptions that other tests for group differences 
Table 1. Construct summary

\begin{tabular}{|l|l|l|}
\hline Construct & Operating definition & Source \\
\hline Age & Single item - age at the time of the survey & Demographic data \\
\hline $\begin{array}{l}\text { Privacy Protection } \\
\text { Competence }\end{array}$ & $\begin{array}{l}\text { Three-item perception of how competent another } \\
\text { individual is at protecting their privacy }\end{array}$ & $\begin{array}{l}\text { (Drake et al., 2016; } \\
\text { McKnight et al., 2002) }\end{array}$ \\
\hline Social Media Production & $\begin{array}{l}\text { Eight-item measure of the extent to which an individual } \\
\text { creates new SNS content }\end{array}$ & New instrument \\
\hline Trusting Stance & $\begin{array}{l}\text { Three item measure of general, i.e. not situation } \\
\text { specific, inclination to display faith in humanity and to } \\
\text { adopt a trusting stance toward others }\end{array}$ & (McKnight et al., 2002) \\
\hline Trust in Employer & $\begin{array}{l}\text { Seven-item measure of baseline trust level in the } \\
\text { employer }\end{array}$ & (Sarker et al., 2011) \\
\hline Hesitancy to Accept & $\begin{array}{l}\text { Two-item measure of how hesitant the participant would } \\
\text { be to accept the job offer. }\end{array}$ & New instrument \\
\hline
\end{tabular}

exhibit (Henseler, 2012). This technique provides a means for testing for moderation of direct effects across groups. Using PLS-MGA, we test our moderation hypotheses.

In order to test our hypotheses, we performed a two-step confirmation, first assessing the outer model for reliability and validity, then second, assessing the inner model for effect sizes and significance (Chin, 1998). In PLS, there are five tests to assess reliability and validity of reflective constructs, 1) composite reliability $>.6$ for all constructs, 2) AVE $>.5$ for all constructs, 3) HTMT $<0.9,4)$ the absolute standardized outer loadings $>.5$, and 5) all cross-loadings should be less than its respective latent variable (Henseler, Ringle, \& Sinkovics, 2009). All reflective constructs had a composite reliability $>=.60$ and AVE $>=.50$ for all three groups (see Table 2 ). The latent constructs

\section{Figure 2. Participants' age}

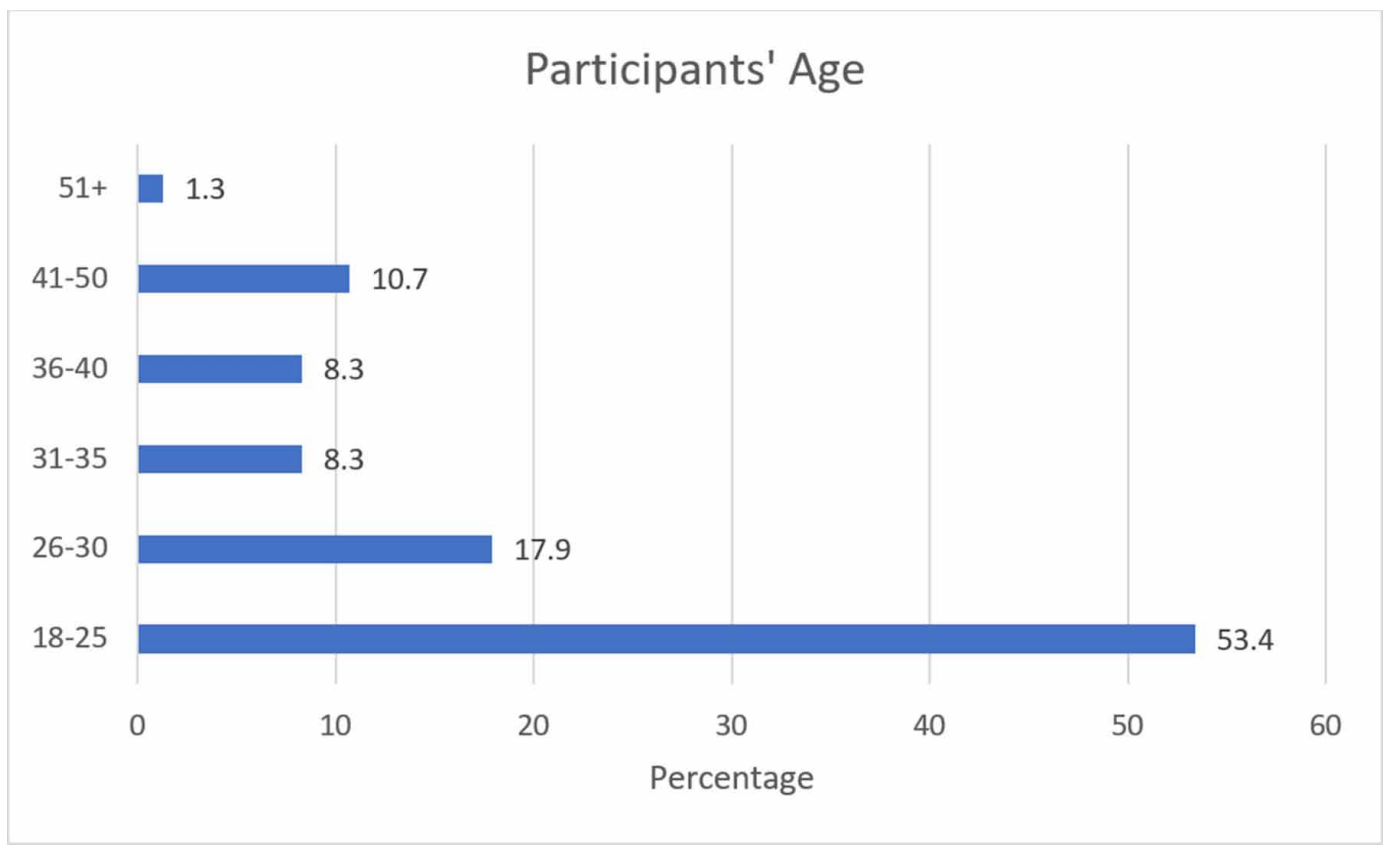


Figure 3. Participants' gender

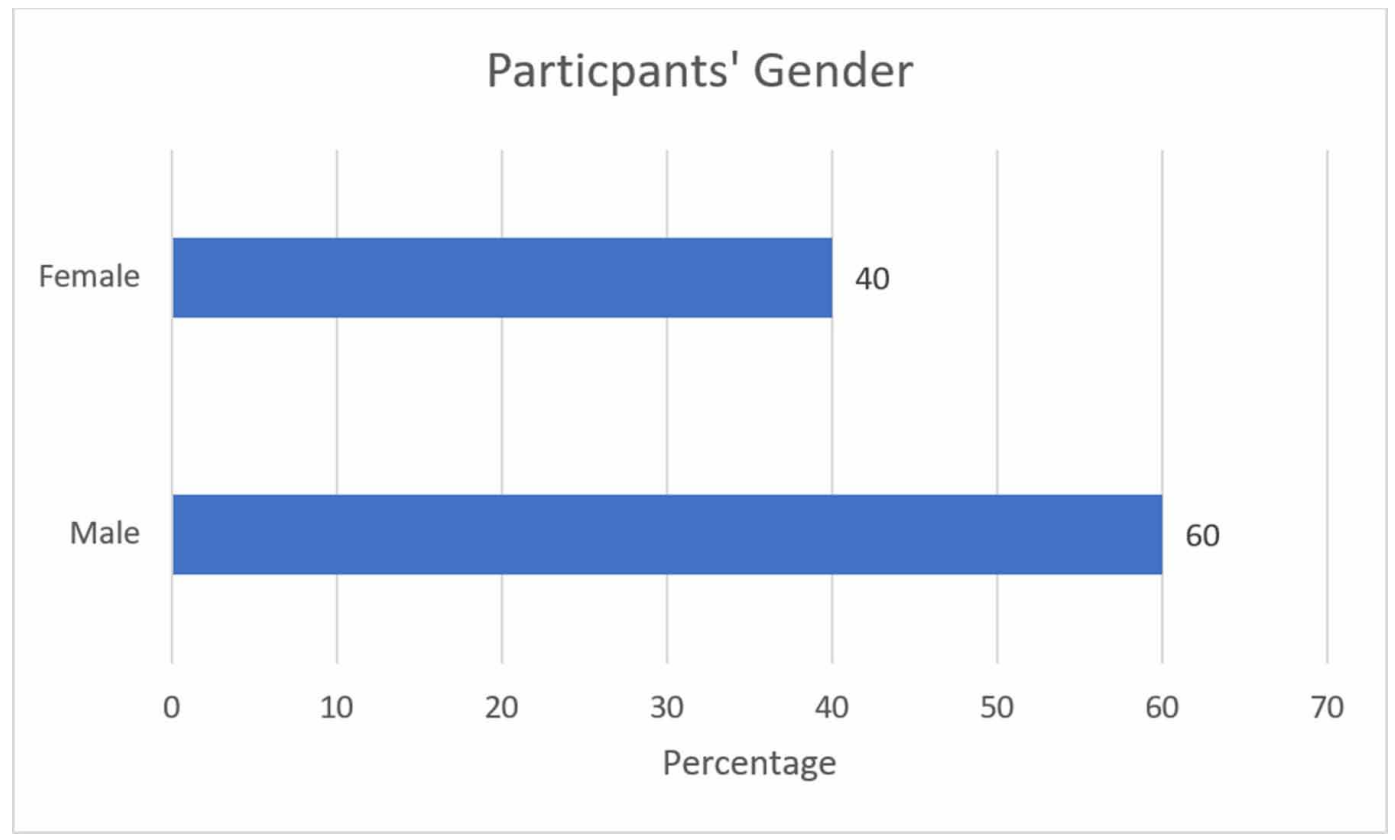

passed HTMT, ensuring discriminant validity (see Table 3). Lastly, all indicators exhibited outer loadings greater than .7 and cross-loadings less than the outer loading (table omitted for brevity). Because Social Media Production is a formative indicator, the outer model was analyzed with 1)

Figure 4. Participants' education

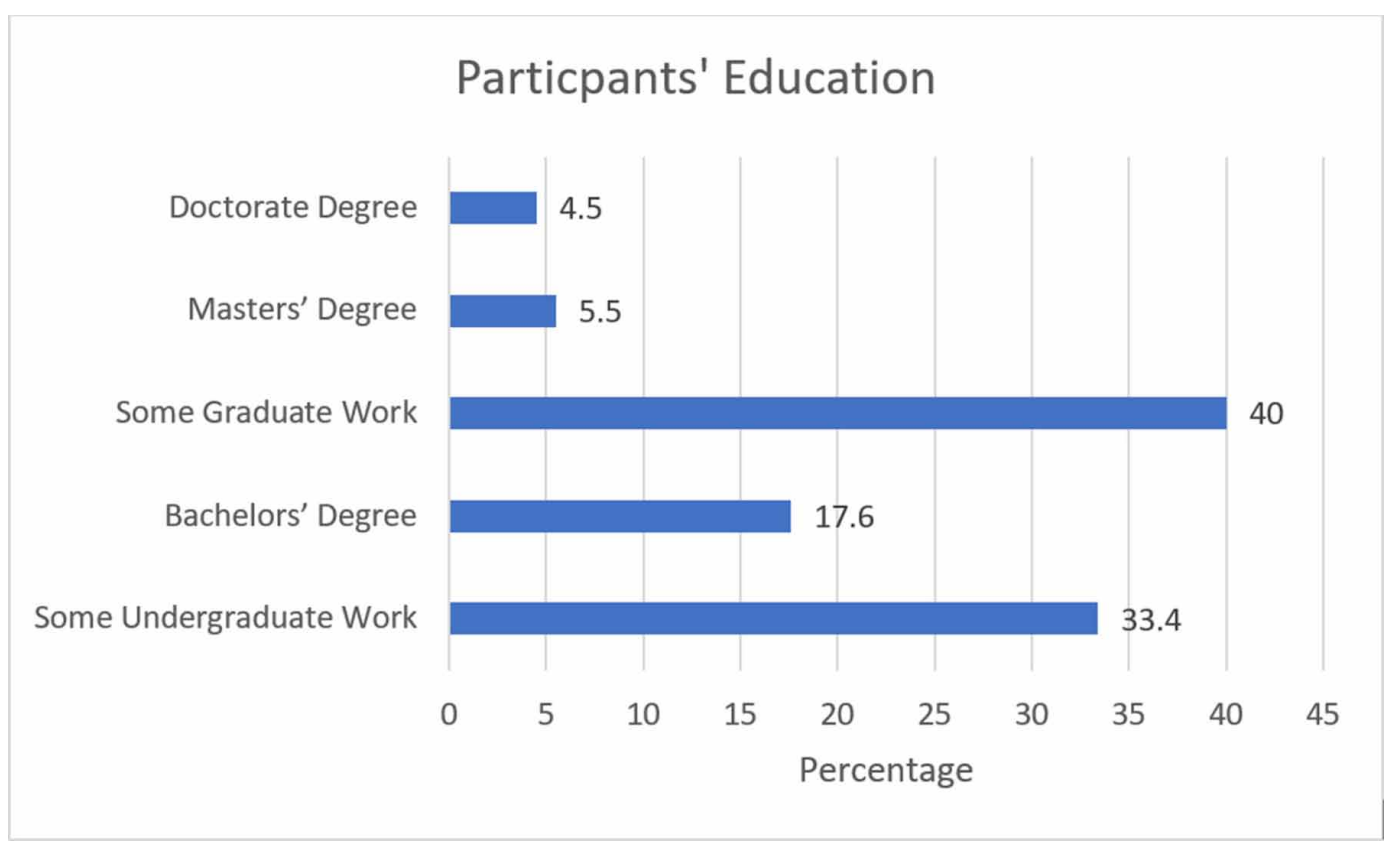


Table 2. Means, Standard Deviations, Reliability, and AVE for constructs in each experimental group

\begin{tabular}{|c|c|c|c|c|}
\hline Latent variables & Measure & View request & Connection request & Password request \\
\hline \multirow{4}{*}{$\begin{array}{l}\text { Privacy Protection } \\
\text { Competence }\end{array}$} & Composite Reliability & .865 & .898 & .902 \\
\hline & AVE & .684 & .746 & .755 \\
\hline & Mean & 4.69 & 4.66 & 4.70 \\
\hline & St. Dev. & 1.17 & 1.18 & 1.18 \\
\hline \multirow{4}{*}{$\begin{array}{l}\text { Social Media } \\
\text { Production }\end{array}$} & Composite Reliability & N/A & N/A & N/A \\
\hline & AVE & N/A & N/A & N/A \\
\hline & Mean & 2.14 & 2.08 & 2.08 \\
\hline & St. Dev. & 0.60 & 0.68 & 0.67 \\
\hline \multirow[t]{4}{*}{ Trusting Stance } & Composite reliability & .905 & .785 & .917 \\
\hline & AVE & .761 & .575 & .786 \\
\hline & Mean & 3.71 & 3.86 & 4.12 \\
\hline & Std. Dev. & 1.38 & 1.22 & 1.37 \\
\hline \multirow[t]{4}{*}{ Trust } & Composite Reliability & .934 & .944 & .954 \\
\hline & AVE & .671 & .705 & .748 \\
\hline & Mean & 4.36 & 4.15 & 3.62 \\
\hline & St. Dev. & 0.98 & 0.99 & 1.16 \\
\hline \multirow{4}{*}{$\begin{array}{l}\text { Hesitancy to } \\
\text { Accept }\end{array}$} & Composite Reliability & .915 & .895 & .911 \\
\hline & AVE & .843 & .810 & .837 \\
\hline & Mean & 3.21 & 3.45 & 4.76 \\
\hline & St. Dev. & 1.68 & 1.59 & 1.58 \\
\hline
\end{tabular}

redundancy analysis demonstrating $\mathrm{R}^{2}>.64,2$ ) all items must exhibit a VIF between 0.2 and 5 , and 3 ) all items should have an outer loading $>5$ or show significance (Hair et al., 2014). The redundancy analysis passed with $\mathrm{R}^{2}=1.0$ showing convergent validity. After performing the discriminant validity analyses, three items were removed. The values of the remaining items passed the discriminant validity tests, summarized in Table 4.

Following our validity checks, we tested the path model, first with gender as a control. Gender showed no significant relationship with the dependent variables, so it was omitted for the remainder of the analysis to avoid erroneous influence (Spector \& Brannick, 2011). Significance of the path estimates was calculated using a bootstrap with 5000 re-samples. Table 5 summarizes the test of

\section{Table 3. Assessment of HTMT}

\begin{tabular}{|l|l|l|l|l|}
\hline & Age & Competence & Hesitant to Accept & Trust \\
\hline $\begin{array}{l}\text { Privacy protection } \\
\text { competence }\end{array}$ & 0.108 & & & \\
\hline Hesitancy to accept & 0.242 & 0.195 & & \\
\hline Trust in employer & 0.437 & 0.330 & 0.652 & \\
\hline Trusting stance & 0.164 & 0.495 & 0.046 & 0.285 \\
\hline
\end{tabular}


Table 4. Social media production item analysis

\begin{tabular}{|l|l|l|l|}
\hline Item & VIF & Outer Weight & Outer Loading \\
\hline 1 - Create blog & 1.467 & 0.115 & $0.369 *$ \\
\hline 2- Comment on blog & 1.426 & 0.038 & $0.358 *$ \\
\hline $3-$ Like micro-blog posts & 2.637 & $0.706 * *$ & $0.946 * *$ \\
\hline $\begin{array}{l}7-\text { Write post on micro- } \\
\text { blog }\end{array}$ & 1.183 & 0.160 & $0.836 * *$ \\
\hline $\begin{array}{l}8-\text { Write post on social } \\
\text { networking site }\end{array}$ & 1.152 & 0.234 & $0.553 * *$ \\
\hline
\end{tabular}

${ }^{*} p<.05,{ }^{* *} p<.01,{ }^{* * *} p<.001$

hypotheses for direct effects in the full model and for each experimental group. The amount of variance explained is provided by adjusted $\mathrm{R}^{2}$ values. Table 6 summarizes the test for moderation between the intrusiveness of the request. Each column captures the path coefficient difference between types of requests and whether those differences are significant. The results find support for all of our main hypotheses and partial support for our moderating hypotheses (see Table 7).

\section{DISCUSSION}

Our study is a direct response to call by Kluemper et al. (2015, p. 75), which concludes with "It is clear from the literature that the use of SNSs by practitioners for selection purposes has been on the rise, yet academic efforts to inform practice are lacking and sorely needed." Our findings that trust in the recruiting company leads candidates to be less hesitant to accept a job offer is an important advancement of this emerging area of study. Our first research question sought to develop an understanding of the ways in which social media screening by recruiters influences candidates' trust and hesitancy to accept job offers. Generally speaking, we found that very invasive social media requests substantially reduced trust and increased hesitancy to accept a job offer. Our second research question sought to identify job candidate characteristics that influence trust in the recruiter and hesitancy to accept a job offer. We were able to identify 4 candidate characteristics which influenced

Table 5. PLS bootstrap results for full model and each experimental group

\begin{tabular}{|l|l|l|l|l|}
\hline & $\begin{array}{l}\text { No Moderation } \\
(\mathbf{n = 2 9 0})\end{array}$ & $\begin{array}{l}\text { View request } \\
(\mathbf{N = 9 7 )}\end{array}$ & $\begin{array}{l}\text { Connection } \\
\text { request }(\mathbf{N = 9 7 )}\end{array}$ & $\begin{array}{l}\text { Password } \\
\text { request } \\
(\mathbf{N = 9 6 )}\end{array}$ \\
\hline Age $->$ trust in employer & $-0.332^{* * *}$ & $-0.414^{* * *}$ & $-0.255^{*}$ & $-0.274^{* *}$ \\
\hline $\begin{array}{l}\text { Privacy protection competence }-> \\
\text { trust in employer }\end{array}$ & $0.189^{* *}$ & $0.229^{*}$ & 0.192 & 0.125 \\
\hline Sm production $->$ trust in employer & $0.145^{* *}$ & 0.018 & $0.218^{*}$ & $0.258^{* *}$ \\
\hline Trusting stance $->$ trust in employer & $0.136^{* *}$ & 0.106 & 0.133 & $0.321^{* * *}$ \\
\hline Trust $r^{2}$ & $28.1 \%$ & $34.6 \%$ & $29.1 \%$ & $45.6 \%$ \\
\hline Trust $->$ Hesitancy to accept & $-0.575^{* * *}$ & $-0.590^{* * *}$ & $-0.436^{* * *}$ & $-0.556^{* * *}$ \\
\hline Hesitancy to accept $r^{2}$ & $33.1 \%$ & $32.3 \%$ & $19.4 \%$ & $31.0 \%$ \\
\hline
\end{tabular}


Table 6. PLS-MGA - absolute difference between experimental groups

\begin{tabular}{|l|l|l|l|}
\hline \multirow{2}{*}{ Path } & \multicolumn{2}{|l|}{ Difference between } \\
\cline { 2 - 4 } & $\begin{array}{l}\text { Connection } \\
\text { Request - } \\
\text { Password Request }\end{array}$ & $\begin{array}{l}\text { Connection } \\
\text { Request - View } \\
\text { Request }\end{array}$ & $\begin{array}{l}\text { Password Request } \\
\text { - View Request }\end{array}$ \\
\hline Age $->$ trust in employer & 0.018 & 0.158 & 0.140 \\
\hline $\begin{array}{l}\text { Privacy protection Competence }->\text { trust in } \\
\text { employer }\end{array}$ & 0.067 & 0.037 & 0.104 \\
\hline Sm production $->$ trust in employer & 0.041 & 0.200 & $0.240^{*}$ \\
\hline Trusting stance $->$ trust in employer & 0.188 & 0.027 & $0.215^{* *}$ \\
\hline Trust $->$ Hesitancy to accept & 0.119 & $0.154^{*}$ & 0.035 \\
\hline
\end{tabular}

${ }^{*} p<.1,{ }^{* *} p<.05,{ }^{* * *} p<.01$

trust directly (age, privacy production competence, social media production and trusting stance). These results are discussed in detail below.

Regardless of the request type, all main effects were supported by the analysis. Age, privacy protective competence, social media production, and trusting stance impact trust in the employer. Younger job candidates put more trust in an employer than older candidates. Job candidates that perceive employers as more competent at privacy protection trust them more. Lastly, job candidates that produce more social media content and have higher trusting stance exhibit more trust in the employer.

Our three experimental groups, which were subjected to varying levels of social media screening, exhibited three different patterns of trust in the hiring organization. In all groups, the age of the participant significantly impacted trust in the organization. Generally, younger participants were more likely to trust the hiring organization, with no significant differences between experimental groups. While trust in the organization had a significant and negative impact on the hesitancy to accept the job offer, the other three factors, privacy protection competence, social media production, and trusting stance with private information, varied in terms of their influence on the candidates' trust in the recruiting organization. We discuss each group in turn.

Table 7. Summary of results

\begin{tabular}{|l|l|}
\hline Hypothesis & Significance \\
\hline H1 & Supported \\
\hline H1A-C & Not supported \\
\hline H2 & Supported \\
\hline H2a-C & Not supported \\
\hline H3 & Supported \\
\hline H3C & Supported \\
H3A-B & Not supported \\
\hline H4 & Supported \\
\hline H4C & Supported \\
H4A-B & Not Support \\
\hline H5 & Supported \\
\hline H5A & Supported \\
H5B-C & Not Supported \\
\hline
\end{tabular}




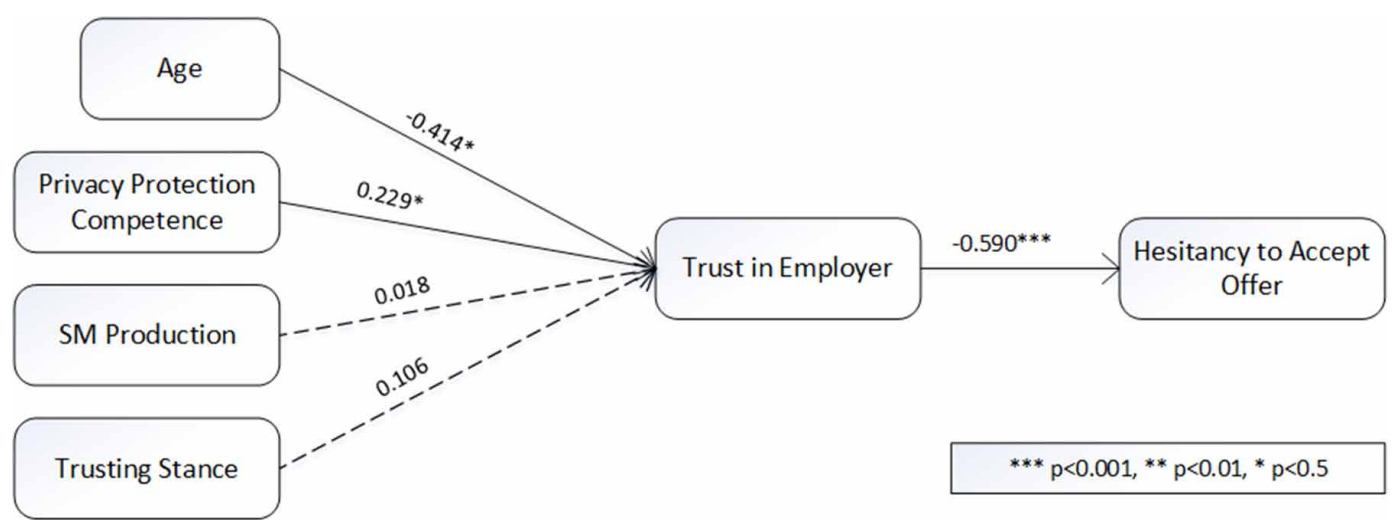

For participants who were told that the hiring organization would view their social media profile, only the perceived competence of professionals in keeping information private had any additional impact on trust in the company after the request (see Figure 5). Viewing the SM content was considered the least intrusive of the three experimental controls. In such situations, the amount of social media produced and the trusting stance of the job candidate had no significant impact on their trust in the hiring organization. This could be because of the limited nature of potential exposure in this situation made the social media production of the candidate irrelevant, since much of that content would either not be seen by the recruiter or if seen, considered a natural consequence of social media production. Surprisingly, trusting stance had no impact on trust in the employer.

For participants who were told that the hiring organization would connect with their social media profile, only the perceived social media production had any impact on the trust in the hiring company after the request (see Figure 6). Connecting through SM was considered to be the $2^{\text {nd }}$ most intrusive of the three experimental controls. In these scenarios, the amount of perceived competence in professionals and the trusting stance of the job candidate had no significant impact on their trust in the hiring organization. It stands to reason that social media production would influence trust, since the recruiter would see the content created by candidate, providing the candidate with an opportunity to engage in impression management using their social media profile. Interestingly Privacy Protection Competence did not influence trust in the employer, perhaps because in this scenario, the candidate's created content did not reach the level of concern as the employer's ability to protect the information they now have access to. Likewise, trusting stance did not impact trust in the employer, perhaps because trusting stance was irrelevant in this situation. More research into the causes of these findings is warranted.

For participants who were told that the hiring organization wanted the password to their social media profile, both the trusting stance and social media production had an impact on the trust in the company after the request (see Figure 7). Requesting login information for SM accounts was considered the most intrusive of the three experimental controls. In such situations, the amount of competence of the professionals had no significant impact on their trust in the hiring organization. This stands to reason, since trust was generally lower in this group than in other groups, with little variance, making the identification of relationships between Trust and other Variables difficult. However, higher social media production led to higher trust, perhaps because participants felt they had nothing to hide.

Unsurprisingly, trust was very low in situations where the recruiter asked for social media passwords. This is consistent with previous research that shows that such requests initiate various information privacy protective responses (Drake et al., 2016). In such situations, only the initial trusting stance predicts the level of trust in the organization after the request. 
Figure 6. SM connection request experimental group

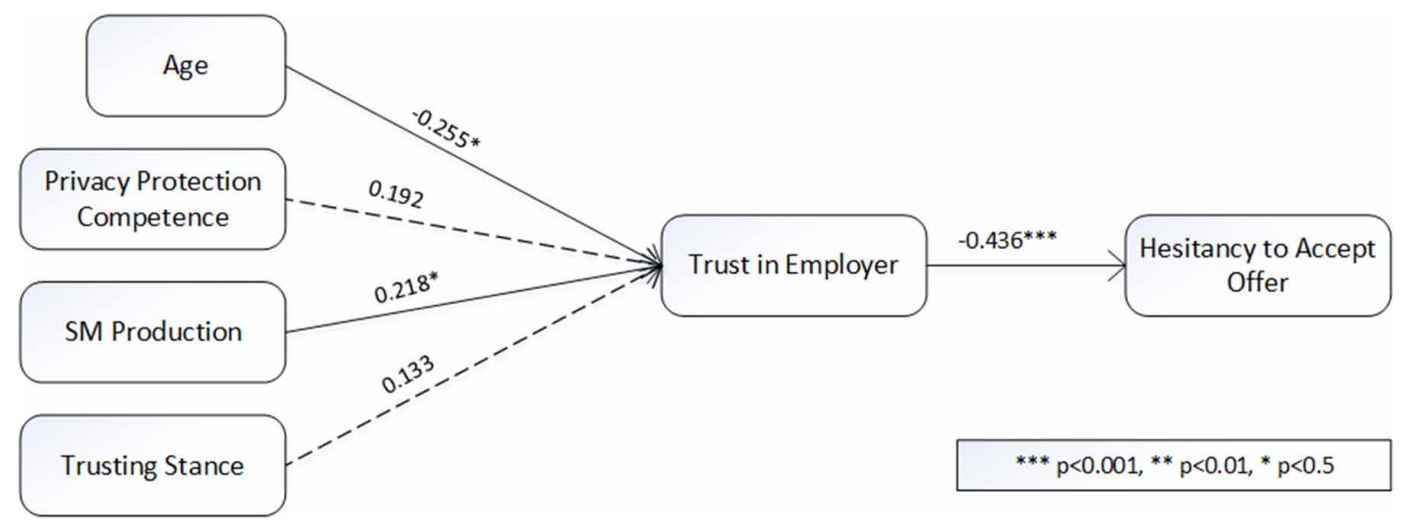

It is worth noting that while no studies indicate how common the practice is, the extent to which recruiters are asking for SNS passwords seems to be relatively limited. According to Gould et al. (2012) the popular press picked up on the trend after candidates who had applied to two employers (the city of Bozeman, MT and the Maryland Department of Corrections) went public about the request in 2009. In 2009, unemployment in the US was increasing and employers had a substantial degree of bargaining power. Since then, labor markets have recovered, and the potential of public backlash may discourage employers from engaging in the practice. Our findings suggest that while the practice might be effective in reducing uncertainty about the candidate, asking for SNS passwords is likely to result in costs related to trust and goodwill. Since reduced trust and enhanced risk to privacy violations affect the intention and actual disclosure of personal information (Zimmer, Arsal, Al-Marzouq, Moore, \& Grover, 2010), requesting social media login credentials may make the recruiters job harder. The request, rather than helping the recruiter learn more about the job candidate, may cause the job candidate to reveal less about themselves or implement various Internet privacy protective responses (Son \& Kim, 2008). Furthermore, the request itself is often considered immoral (Drake, 2016), and may lead high quality job candidates to withdraw themselves from consideration. Taken together, this implies that employers should avoid asking for SNS passwords except in hiring situations involving substantial security risks.

While this study represents an early step in our understanding of the dynamics involved in recruiting and selection during the age of social media, it does carry some implications for practitioners.

Figure 7. SM password request experimental group

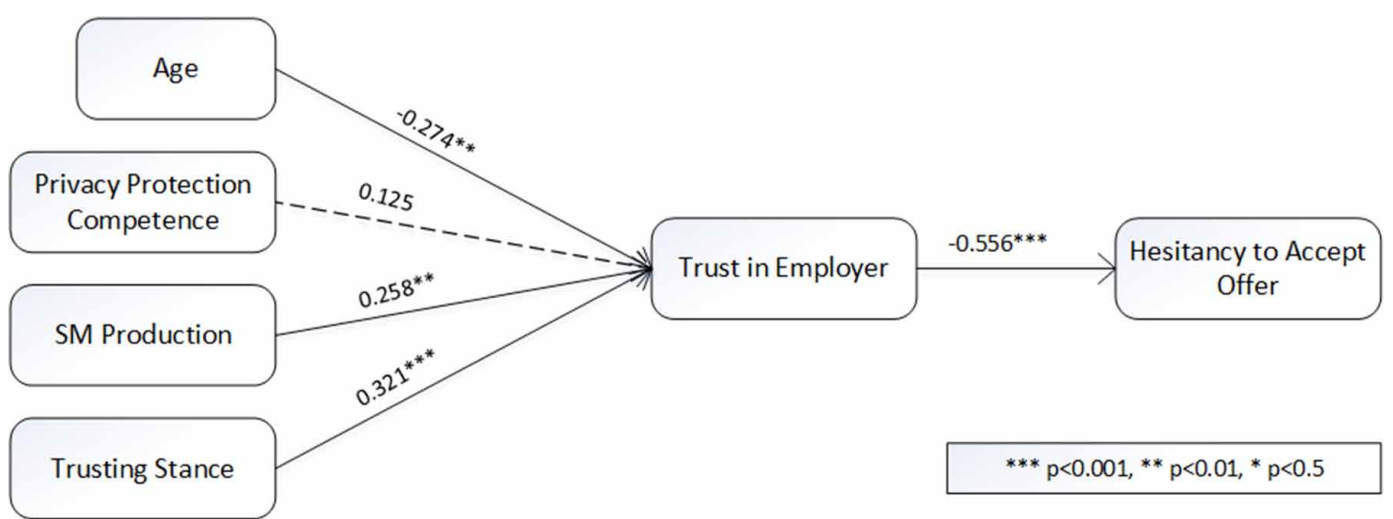


Since recruiting, screening and interviewing candidates represents a substantial cost for organizations in terms of both time and financial costs, and because the potential upside of hiring well qualified candidates is considerable (Brown \& Vaughn, 2011), organizations are motivated to ensure that strong candidates accept offers. Fostering trust in the minds of recruits is important to reduce the hesitancy of candidates to accept an offer, and in many cases, projecting an impression that a company takes privacy seriously and that its capable of protecting it. Further, job candidates don't seem to lose much trust when they are informed that the recruiting company is going to review their public social media profiles, or connect with them on social media, however when they ask for social media passwords, trust levels fall dramatically. This finding is important for recruiters, as it suggests that it is possible to use social media to reduce uncertainty about job candidates, as long as the recruiters do not erode trust by asking for login credentials. As future studies investigate the relationship between candidate characteristics and screening characteristics, more nuanced recommendations for recruiters should evolve.

This study is a first step in addressing the emergence and use of social media for job candidate screening, and the findings raise several new questions for future researchers. While popular media provides evidence that social media screening is common among recruiters, our findings that 1) candidates tend to be agreeable to some forms of social media screening, and that 2) a number of individual level characteristics influence trust in the recruiter as well as hesitancy to accept an offer imply that this trend will likely grow for both its utility to recruiters and acceptance by job candidates. Researchers may consider further evaluating 1) the extent to which candidates know about the level of social media screening influences the outcomes, 2) how other forms of social media screening influence the outcomes and 3) which other individual characteristics influence recruiting outcomes. Through such knowledge, recruiters might better assess how which characteristics to collect and customize the amount of information that they collect about the candidate in order to make a tradeoff between how much uncertainty they reduce and how much the influence the trust of the candidate. For example, if individual characteristics of a particular candidate suggest that she is very sensitive to privacy invasion, and the candidate is otherwise desirable, it might be best not to ask that candidate to "friend" or "like" the company's Facebook presence. However, if the individual characteristics of the candidate suggest that the candidate is unlikely to be troubled by more extensive screening, and if there is value in further screening for uncertainty reduction related to this candidate, it might be worth the tradeoff.

\section{CONCLUSION}

Social media are increasingly used in a variety of information seeking activities, from health information (Li \& Wang, 2018) to commercial product and service reviews (Furner, Zinko, \& Zhu, 2018) as well as a learning tool (Di Gangi, Goh, \& Lewis, 2017). Indeed, the rapid proliferation of social media influences a number of relevant organizational factors, including employee job satisfaction (Kim, 2019). Job candidate screening is an important optimization task which is wrought with uncertainty. While social media facilitates uncertainty reduction, this study suggests that invasive screening of social media may have an unintended consequence, a loss of trust by the candidate, which can foster hesitancy to accept the position. An employer using social media for job screening should take these findings into account. As social media and individual information processing habits continue to evolve, the importance of a robust understanding of job candidates' attitudes toward privacy and the factors which influence their feelings of trust become increasingly tantamount. 


\section{REFERENCES}

Affairs, B. N. (2000). Bulletin to management special report: human resource priorities and outlook. Academic Press.

Aral, S., Dellarocas, C., \& Godes, D. (2013). Introduction to the special issue-social media and business transformation: A framework for research. Information Systems Research, 24(1), 3-13. doi:10.1287/isre.1120.0470

Barrick, M. R., Shaffer, J. A., \& DeGrassi, S. W. (2009). What you see may not be what you get: Relationships among self-presentation tactics and ratings of interview and job performance. The Journal of Applied Psychology, 94(6), 1394-1411. doi:10.1037/a0016532 PMID:19916651

Bateson, J. E., Wirtz, J., Burke, E. F., \& Vaughan, C. J. (2014). Sifting to efficiently select the right service employees. Organizational Dynamics, 43(4), 312-320. doi:10.1016/j.orgdyn.2014.09.008

Belanger, F., \& Crossler, R. E. (2011). Privacy in the Digital Age: A Review of Information Privacy Research in Information Systems. Management Information Systems Quarterly, 35(4), 1017-1041. doi:10.2307/41409971

Berger, C. R. (1979). Beyond initial interaction: Uncertainty, understanding, and the development of interpersonal relationships. In Language and social psychology (pp. 122-144). Academic Press.

Bohler, J. A., \& Drake, J. R. (2017). Building Trust through Social Networking. Paper presented at the Americas' Conference on Information Systems. Academic Press.

Brown, V. R., \& Vaughn, E. D. (2011). The writing on the (Facebook) wall: The use of social networking sites in hiring decisions. Journal of Business and Psychology, 26(2), 219-225. doi:10.1007/s10869-011-9221-x

Celani, A., Deutsch-Salamon, S., \& Singh, P. (2008). In justice we trust: A model of the role of trust in the organization in applicant reactions to the selection process. Human Resource Management Review, 18(2), 63-76. doi:10.1016/j.hrmr.2008.04.002

Chapman, D. S., \& Webster, J. (2003). The use of technologies in the recruiting, screening, and selection processes for job candidates. International Journal of Selection and Assessment, 11(2-3), 113-120. doi:10.1111/14682389.00234

Chen, C.-C., Wen-Fen Yang, I., \& Lin, W.-C. (2010). Applicant impression management in job interview: The moderating role of interviewer affectivity. Journal of Occupational and Organizational Psychology, 83(3), 739-757. doi:10.1348/096317909X473895

Chin, W. W. (1998). The partial least squares approach to structural equation modeling. Modern methods for business research, 295(2), 295-336.

Colquitt, J. A., Scott, B. A., \& LePine, J. A. (2007). Trust, trustworthiness, and trust propensity: A meta-analytic test of their unique relationships with risk taking and job performance. The Journal of Applied Psychology, 92(4), 909-927. doi:10.1037/0021-9010.92.4.909 PMID:17638454

Das, T. K., \& Teng, B.-S. (1998). Between trust and control: Developing confidence in partner cooperation in alliances. Academy of Management Review, 23(3), 491-512. doi:10.5465/amr.1998.926623

De Cremer, D., \& Tyler, T. R. (2007). The effects of trust in authority and procedural fairness on cooperation. The Journal of Applied Psychology, 92(3), 639-649. doi:10.1037/0021-9010.92.3.639 PMID:17484547

Dewan, S., \& Ramaprasad, J. (2014). Social media, traditional media, and music sales. Management Information Systems Quarterly, 38(1), 101-121. doi:10.25300/MISQ/2014/38.1.05

Di Gangi, P. M., Goh, S. H., \& Lewis, C. C. (2017). Using Social Media to Support Presentation Skill Development in Traditional Classroom Environments. Journal of Organizational and End User Computing, 29(3), 68-91. doi:10.4018/JOEUC.2017070104

Dirks, K. T., \& Ferrin, D. L. (2001). The role of trust in organizational settings. Organization Science, 12(4), 450-467. doi:10.1287/orsc.12.4.450.10640

Dirks, K. T., \& Ferrin, D. L. (2002). Trust in leadership: Meta-analytic findings and implications for research and practice. The Journal of Applied Psychology, 87(4), 611-628. doi:10.1037/0021-9010.87.4.611 PMID:12184567 
Drake, J. R. (2016). Asking for Facebook Logins: An Egoist Case for Privacy. Journal of Business Ethics, 139(3), 429-441. doi:10.1007/s10551-015-2586-4

Drake, J. R., Hall, D. J., Becton, B., \& Posey, C. (2016). Job Applicants' Information Privacy Protection Responses: Using Social Media for Candidate Screening. AIS Transactions on HCI, 8(4), 160-184.

Duffy, D. J. (1982). Privacy vs disclosure-balancing employee and employer rights. Employee Relations Law Journal, 7(4), 594-609.

Duggan, M., \& Brenner, J. (2013). The Demographics of Social Media Users - 2012. Pew Internet Center. Retrieved from http://pewinternet.org/Reports/2013/Social-media-users.aspx

Dutta, S. (2010). What's your personal social media strategy. Harvard Business Review, 88(11), 127-130. PMID:21049685

Eskildsen, J. K., \& Dahlgaard, J. J. (2000). A causal model for employee satisfaction. Total Quality Management, 11(8), 1081-1094. doi:10.1080/095441200440340

Fisher, C. D., Ilgen, D. R., \& Hoyer, W. D. (1979). Source Credibility, Information Favorability, and Job Offer Acceptance1. Academy of Management Journal, 22(1), 94-103.

Furner, C. P., \& George, J. F. (2009). Making it hard to lie: Cultural determinants of media choice for deception. Paper presented at the 2009 42nd Hawaii International Conference on System Sciences. Academic Press.

Furner, C. P., \& George, J. F. (2012). Cultural determinants of media choice for deception. Computers in Human Behavior, 28(4), 1427-1438. doi:10.1016/j.chb.2012.03.005

Furner, C. P., Racherla, P., \& Zhu, Z. (2014). A multinational study of espoused national cultural and review characteristics in the formation of trust in online product reviews. International Journal of Services Technology and Management, 20(1/2/3), 14-30.

Furner, C. P., Zinko, R., \& Zhu, Z. (2018). Examining the Role of Mobile Self-Efficacy in the Word-of-Mouth/ Mobile Product Reviews Relationship. International Journal of E-Services and Mobile Applications, 10(4), 40-60. doi:10.4018/IJESMA.2018100103

Gefen, D. (2000). E-Commerce: The Role of Familiarity and Trust. Omega, 28(6), 725-737. doi:10.1016/ S0305-0483(00)00021-9

Gefen, D., Rigdon, E. R., \& Straub, D. W. (2011). An Update and Extension to SEM Guidelines for Administrative and Social Science Research. Management Information Systems Quarterly, 35(2), iii-xiv. doi:10.2307/23044042

Gibbs, C., MacDonald, F., \& MacKay, K. (2015). Social media usage in hotel human resources: Recruitment, hiring and communication. International Journal of Contemporary Hospitality Management, 27(2), 170-184. doi:10.1108/IJCHM-05-2013-0194

Gould, A. M., Goren, W. D., Frederick, J., Myers, V., Gordon, N. J., Loeffler, M. H., \& Popular, S. (2012). If You're Asking for the Facebook Passwords of Job Candidates. You're Asking for Trouble.

Grasz, J. (2009). Forty-five percent of employers use social networking sites to research job candidates, CareerBuilder survey finds. CareerBuilder Press Releases.

Hair, J. F., Hult, G. T. M., Ringle, C. M., \& Sarstedt, M. (2014). A Primer on Partial Least Squares Structural Equation Modeling (PLS-SEM) (1st ed.). Los Angeles, CA: Sage Publications.

Henseler, J. (2012). PLS-MGA: A non-parametric approach to partial least squares-based multi-group analysis. In Challenges at the interface of data analysis, computer science, and optimization (pp. 495-501). Springer.

Henseler, J., Ringle, C. M., \& Sinkovics, R. R. (2009). The use of partial least squares path modeling in international marketing. Advances in International Marketing, 20, 277-320. doi:10.1108/S1474-7979(2009)0000020014

Hunter, S. D. (2011). Pricing banner advertisements in a social network of political weblogs. Journal of Information Technology Theory and Application, 12(2), 5-23.

Johnson-George, C., \& Swap, W. C. (1982). Measurement of specific interpersonal trust: Construction and validation of a scale to assess trust in a specific other. Journal of Personality and Social Psychology, 43(6), 1306-1317. doi:10.1037/0022-3514.43.6.1306 
Keith, M. J., Babb, J., Furner, C., Abdullat, A., \& Lowry, P. B. (2016). Limited information and quick decisions: Consumer privacy calculus for mobile applications. AIS Transactions on Human-Computer Interaction, 8(3), 88-130. doi:10.17705/1 thci.00081

Kim, H. (2019). Investigating the Mediating Role of Social Networking Service Usage on the Big Five Personality Traits and on the Job Satisfaction of Korean Workers. Journal of Organizational and End User Computing, 31(1), 110-123. doi:10.4018/JOEUC.2019010106

Kluemper, D. H., Davison, H. K., Cao, X., \& Wu, B. (2015). Social networking websites and personnel selection: A call for academic research. Employee Recruitment, Selection, and Assessment: Contemporary Issues for Theory and Practice, 61.

Kluemper, D. H., Rosen, P. A., \& Mossholder, K. W. (2012). Social networking websites, personality ratings, and the organizational context: More than meets the eye? 1. Journal of Applied Social Psychology, 42(5), 1143-1172. doi:10.1111/j.1559-1816.2011.00881.x

Kristof-Brown, A. L. (2000). Perceived applicant fit: Distinguishing between recruiters' perceptions of person-job and person-organization fit. Personnel Psychology, 53(3), 643-671. doi:10.1111/j.1744-6570.2000.tb00217.x

Lauver, K. J., \& Kristof-Brown, A. (2001). Distinguishing between employees' perceptions of person-job and person-organization fit. Journal of Vocational Behavior, 59(3), 454-470. doi:10.1006/jvbe.2001.1807

Levashina, J., \& Campion, M. A. (2009). Expected practices in background checking: Review of the human resource management literature. Employee Responsibilities and Rights Journal, 21(3), 231-249. doi:10.1007/ s10672-009-9111-9

Li, Y., \& Wang, X. (2018). Seeking health information on social media: A perspective of trust, selfdetermination, and social support. Journal of Organizational and End User Computing, 30(1), 1-22. doi:10.4018/ JOEUC.2018010101

Mael, F. A., Connerley, M., \& Morath, R. A. (1996). None of your business: Parameters of biodata invasiveness. Personnel Psychology, 49(3), 613-650. doi:10.1111/j.1744-6570.1996.tb01587.x

McKnight, D. H., Choudhury, V., \& Kacmar, C. (2002). Developing and Validating Trust Measures for e-Commerce: An Integrative Typology. Information Systems Research, 13(3), 334-359. doi:10.1287/ isre.13.3.334.81

McKnight, D. H., Cummings, L. L., \& Chervany, N. L. (1998). Initial Trust Formation in New Organizational Relationships. Academy of Management Review, 23(3), 473-490. doi:10.5465/amr.1998.926622

Mooradian, T., Renzl, B., \& Matzler, K. (2006). Who trusts? Personality, trust and knowledge sharing. Management Learning, 37(4), 523-540. doi:10.1177/1350507606073424

Morgan, R. M., \& Hunt, S. D. (1994). The commitment-trust theory of relationship marketing. Journal of Marketing, 58(3), 20-38. doi:10.1177/002224299405800302

Nichos, T., Danford, A., \& Tasiran, A. C. (2009). Trust, Employer Exposure, and the Employment Relation. Economic and Industrial Democracy, 30(2), 241-265. doi:10.1177/0143831X09102429

O’Dell, J. (2012). Recruitment Trend We Hate: Asking for Facebook Passwords During the Interview. Venturebeat. Retrieved from http://venturebeat.com/2012/03/21/facebook-login-job-interview/

Ollington, N., Gibb, J., \& Harcourt, M. (2013). Online social networks: An emergent recruiter tool for attracting and screening. Personnel Review, 42(3), 248-265. doi:10.1108/00483481311320390

Pavlou, P. A. (2003). Consumer Acceptance of Electronic Commerce: Integrating Trust and Risk with the Technology Acceptance Model. International Journal of Electronic Commerce, 7(3), 101-134. doi:10.1080/1 0864415.2003 .11044275

Peters, S., Straub, D. W., \& Rai, A. (2007). Specifying Formative Constructs in Information Systems Research. Management Information Systems Quarterly, 31(4), 623-656. doi:10.2307/25148814

Pham, L. M. T., Tran, L. T.-T., Thipwong, P., \& Huang, W. T. (2019). Dynamic Capability and Organizational Performance: Is Social Networking Site a Missing Link? Journal of Organizational and End User Computing, 31(2), 1-21. doi:10.4018/JOEUC.2019040101 
Poncy, G., Kim, M., Ramos, K., \& Lopez, F. G. (2017). Career Planning Confidence Among Facebook Users: Contributions of Adult Attachment Security and Authenticity. Journal of Career Assessment, 1-17.

Robinson, S. L. (1996). Trust and Breach of the Psychological Contract. Administrative Science Quarterly, 41(4), 574-599. doi:10.2307/2393868

Rogers, R. W. (1975). A protection motivation theory of fear appeals and attitude change. The Journal of Psychology, 91(1), 93-114. doi:10.1080/00223980.1975.9915803 PMID:28136248

Rotter, J. B. (1971). Generalized expectancies for interpersonal trust. The American Psychologist, 26(5), 443-452. doi: $10.1037 / \mathrm{h} 0031464$

Rowell, E. (2010). Didn't get hired because of Facebook? You're not alone. Ezine Articles, 10.

Saks, A. M. (1989). An examination of the combined effects of realistic job previews, job attractiveness and recruiter affect on job acceptance decisions. Applied Psychology, 38(2), 145-163. doi:10.1111/j.1464-0597.1989. tb01206.x

Sampson, J. P. Jr, \& Lumsden, J. A. (2000). Ethical Issues in the Design and Use of Internet-Based Career Assessment. Journal of Career Assessment, 8(1), 21-35. doi:10.1177/106907270000800103

Sarker, S., Ahuja, M., Sarker, S., \& Kirkeby, S. (2011). The role of communication and trust in global virtual teams: A social network perspective. Journal of Management Information Systems, 28(1), 273-310. doi:10.2753/ MIS0742-1222280109

Sekiguchi, T. (2004). Person-organization fit and person-job fit in employee selection: A review of the literature. Osaka Keidai Ronshu, 54(6), 179-196.

Slovensky, R., \& Ross, W. H. (2012). Should human resource managers use social media to screen job applicants? Managerial and Legal Issues in the USA. Info, 14(1), 55-69. doi:10.1108/14636691211196941

Smith, W. P., \& Kidder, D. L. (2010). You've been tagged!(Then again, maybe not): Employers and Facebook. Business Horizons, 53(5), 491-499. doi:10.1016/j.bushor.2010.04.004

Son, J.-Y., \& Kim, S. S. (2008). Internet Users' Information Privacy-Protective Responses: A Taxonomy and a Nomological Model. Management Information Systems Quarterly, 32(3), 503-529. doi:10.2307/25148854

Spector, P. E., \& Brannick, M. T. (2011). Methodological Urban Legends: The Misuse of Statistical Control Variables. Organizational Research Methods, 14(2), 287-305. doi:10.1177/1094428110369842

Stewart, K. A., \& Segars, A. H. (2002). An empirical examination of the concern for information privacy instrument. Information Systems Research, 13(1), 36-49. doi:10.1287/isre.13.1.36.97

Suen, H.-Y. (2018). How passive job candidates respond to social networking site screening. Computers in Human Behavior, 85, 396-404. doi:10.1016/j.chb.2018.04.018

Van De Mieroop, D. (2018). Implying identities through narratives of vicarious experience in job interviews. Journal of Pragmatics.

Vatamanescu, E.-M., \& Constantin, I.-F. (2015). Facebook Usage as Social Screening. Exploring the Approach of Admissions Officers from Management Colleges. Management Dynamics in the Knowledge Economy, 3(1), 61.

Vinzi, V. E., Chin, W. W., Henseler, J., \& Wang, H. (2010). Editorial: Perspectives on partial least squares. In Handbook of partial least squares (pp. 1-20). Springer. doi:10.1007/978-3-540-32827-8

Weiss, B., \& Feldman, R. S. (2006). Looking good and lying to do it: Deception as an impression management strategy in job interviews. Journal of Applied Social Psychology, 36(4), 1070-1086. doi:10.1111/j.00219029.2006.00055.x

Ziegler, M., MacCann, C., \& Roberts, R. (2011). New perspectives on faking in personality assessment. Oxford University Press. doi:10.1093/acprof:oso/9780195387476.001.0001

Zimmer, J. C., Arsal, R., Al-Marzouq, M., Moore, D., \& Grover, V. (2010). Knowing your Customers: Using a Reciprocal Relationship to Enhance Voluntary Information Disclosure. Decision Support Systems, 48(2), 395-406. doi:10.1016/j.dss.2009.10.003 
John R. Drake is an Associate Professor of Management Information Systems at East Carolina University. He holds a BS in Physics from Southern Illinois University at Edwardsville and a Ph.D. in Management of Information Technology and Innovation from Auburn University. His research has been published in journals such as AIS Transactions on $\mathrm{HCl}$, Journal of Business Ethics, IEEE Transactions on Professional Communication, Journal of Information Technology Theory and Application, and Journal of Theoretical and Applied Electronic Commerce Research. His current research interest focuses on thinking and morality with information systems, exploring social media privacy, search strategies, online education, and general business ethics. A second research stream focuses on virtual teamwork, exploring the role of trust, risk, and virtuality of teams in successful completion of their project. Dr. Drake is also author of eCommerce: A Stakeholder Approach.

Christopher Furner serves as an Associate Professor of Management Information Systems in the College of Business at East Carolina University. His research interests include mobile computing issues including locationbased privacy, mobile app stickiness and mobile self-efficacy. Dr. Furner also studies cultural determinants of individual level information systems outcomes, such as Knowledge Management System effectiveness, media choice and purchase intention in an e-commerce setting. His research has appeared in Electronic Markets, Information Systems Journal and Computers in Human Behavior, among others. 